RESEARCH WORK

\title{
Influence of the Passive Evaporation of adhesive on the conductance of dentin
}

\author{
Cristian Bersezio ${ }^{1}$, Sebastian Toledo ${ }^{1}$, Claudia Letelier ${ }^{1}$, Andrea Werner ${ }^{1}$, Osmir Batista Oliveira $\mathrm{Jr}^{2}$, \\ Ziyad S Haydar ${ }^{3}$, Javier Martín ${ }^{1}$ and Eduardo Fernández ${ }^{1 *}$
}

1. Departament of Restorative Dentistry, University of Chile, Santiago, Chile.

2. Departament of Restorative Dentistry, UNESP,

Araraquara, Sao Paulo, Brasil.

3. Universidad de Los Andes, Santiago, Chile

Corresponding Author: Eduardo Fernández G. $D D S, D S, P h D \mid$ Department of Restorative Dentistry, Universidad de Chile, Dental school - Sergio Livingstone Pohlhammer 943, Independencia |

Santiago, Chile. | Phone-Fax:+56229462929 |

Email:edofdez@yahoo.com

Trabajo recibido el 10/06/2016. Aprobado para su publicación el 08/02/2017

\begin{abstract}
Aim: Determine the influence of time of passive evaporation of the solvent in a universal adhesive on the hydraulic conductance and permeability of dentin in an ex vivo human model. Henceforth, 60 healthy non-occluding third molars, indicated for therapeutic extraction/removal, of informed and consented patients aged between 18 and 30 years, were used here in. First, extracted teeth were incorporated into epoxy resin blocks and then dentin disks ( $1 \mathrm{~mm}+/-0.1 \mathrm{~mm}$ thick) were prepared. Dentin was acid etched with $35 \%$ orthophosphoric acid for 15 seconds in order to remove the smear layer and obtain permeable dentin. Samples were then randomized and divided into 5 groups $(n=12)$. A Single Bond Universal adhesive layer with different time of passive evaporation of the solvent was then applied: $\mathrm{GC}=10$ seconds, $\mathrm{G} 1=30$ seconds, $\mathrm{G} 2=60$ seconds, $\mathrm{G} 3=300$ seconds and $\mathrm{G} 4=50$ minutes. Finally, the flow rate was measured using a diffusion chamber, a model previously proposed by Pashley et al. Results: The obtained hydraulic conductance averages were as follows: $\mathrm{GC}=0.00052, \mathrm{G} 1=0.00018, \mathrm{G} 2=0.00006, \mathrm{G} 3=0.00005, \mathrm{G} 4=0.00005$ expressed in $\mathrm{uL} \cdot \mathrm{cm}-2 \cdot \mathrm{min}-1 \mathrm{~cm} \cdot \mathrm{H} 2 \mathrm{O}-1$. For comparisons between groups, ANOVA and post hoc Tukey $(\rho<0.05)$ tests were applied, resulting in a statistically significant difference between the GC group and all experimental groups $(\rho<0.05)$. An influence of solvent passive evaporation thereby reducing hydraulic conductance in the experimental groups, was detected.

KEY WORDS
\end{abstract}

Passive evaporation, adhesion, hydraulic conductance.

Rev. Clin. Periodoncia Implantol. Rehabil. Oral Vol. 10(1); 38-40, 2017.

\section{INTRODUCTION}

Exposure of dentinal tubules during cavity preparation procedures is inevitable. Thus, increases in dentin permeability allowing the passage of fluid, ions, molecules, particles and/or bacteria, in and through dentin under different conditions, occurs. This phenomenon is affected or influenced by several factors: multi-factorial. Dental adhesives, is one example. ${ }^{1}$ Indeed, it has been found that the use of adhesive materials in dentin leads to a significant reduction in permeability as an occlusion of the dentinal tubules takes place. ${ }^{2}$

Typically, within the composition of the resinous adhesive systems, monomers are dissolved in solvents such as acetone, ethanol, or water and/or a combination of those, which thereby improves the diffusion of the monomer into the demineralized dentinal matrix. To achieve the formation of a good quality hybrid layer, an 'optimal' infiltration of the monomer between the collagen fibrils should be pursued and obtained; thereby removing as much water and solvent from the surface before polymerization. ${ }^{3,4}$ Indeed, it has been reported that insufficient evaporation of the solvent can generate the formation of micro cracks in the adhesive interface, a loss of mechanical strength, higher water absorption and a lower degree of polymer conversion. ${ }^{5,6}$ Therefore, the evaporation of the solvent facilitates the polymerization reaction. This is mainly due to the (a) reduction in the distance between the monomers and $(b)$ increases in the degree of conversion. ${ }^{7-10}$ Therefore, increasing the drying time may consequently increase or enhance the evaporation of the adhesive solvent. .11, $12^{12}$

While passive evaporation seems to generate (1) a better quality polymer and (2) a better quality seal, theoretically; reducing hydraulic conductance, no studies, to the best of our knowledge, attempt to link this hydraulic conductance phenomenon with the factor of time of passive solvent evaporation of a universal adhesive. This might provide valuable insights for use, application and translation into our clinical practice.

Therefore, the objective of this study is to evaluate the effect of passive solvent evaporation on the hydraulic conductance of the
Universal Single Bond adhesive system, in an ex vivo model. The null hypothesis formulated for this study is as follows: passive solvent evaporation of the adhesive does not affect the hydraulic conductance of dentin.

\section{MATERIAL AND METHODS}

\section{Study design}

This study included a total $\mathrm{N}$ of 60 human third molars extracted from patients aged between 18 and 30 years, who met the following inclusion criteria:

Healthy non-occluding teeth, indicated for extraction. All patients previously read and signed a written informed consent form, approved by the Ethics Committee of the Faculty of Dentistry, University of Chile (PRI-ODO / 12-002).

Extracted teeth were disinfected for 24 hours in a solution of $0.1 \%$ Thymol, then the soft tissues were manually removed using Gracey Curettes $^{13,14}$ (American Eagle, USA) and were preserved in $0.9 \%$ saline solution at room temperature.

Etching of the enamel surface for 30 seconds using 35\% phosphoric acid (Etchant Gel S 35\% Coltene-Whaledent, Switzerland) was performed. Washing with water and drying followed. A layer of cyanoacrylate (Super Ceys Brush applied - Ceys) was then applied prior to inclusion in the block of epoxy to ensure achieving a tight seal.

From each block, a disk of dentin measuring $1 \mathrm{~mm}(+/-0.1 \mathrm{~mm})$ in thickness was obtained using the precision machine (Buehler Isomet 1000 Ler Lakebuff IL, USA), set to $500 \mathrm{r} / \mathrm{min}$., under constant load of $500 \mathrm{gr}$. in weight and with abundant cooling.

To create a standardized substrate on dentin for adhesion, both sides of the dentin disk were regularized using abrasive paper (Silicon Paper No. 600, SIA, Switzerland) under abundant water for 60 seconds. Furthermore, the smear layer was removed via etching using phosphoric acid 35\% (Etchant Gel S 35\% Coltene-Whaledent) for 15 seconds on both sides. This was followed by washing using water for double the time and drying with absorbent paper. 


\section{Experimental groups}

A total $\mathrm{N}$ of 60 dentin disks were randomly distributed, by Microsoft Excel 2013 (Microsoft, Seattle, USA) software into five groups of $n=12$ samples. All groups received a layer of Single Bond Universal (SBU) (3M ESPE, USA) adhesive, waiting for a passive evaporation of:

Group 1 (GC): 10 seconds acted as control

Group 2 (G1): 30 seconds.

Group 3 (G2): 60 seconds.

Group 4 (G3): 300 seconds.

Group 5 (G4): 3000 seconds (50 minutes - complete solvent evaporation by Loguercio et al. ${ }^{13}$ ).

\section{Adhesive application}

A layer of adhesive was applied with a Multi-Brush medium (Dembur Inc. USA) on the occlusal surface of each disc, per the manufacturer's instructions. Vigorous rubbing on dentin for 20 seconds using a multi-brush followed - yet, blowing with the triple syringe was replaced with passive solvent evaporation. Finally, the adhesive was photopolymerized for 20 seconds using an Elipar lamp 2500 (3M Espe, USA).

\section{Measurement of Hydraulic Conductance}

The flow rate was determined by an experimental model implemented by Pashley et al. In the diffusion chamber set under constant pressure of a water column of $20 \mathrm{~cm}$, the measurement was performed for 20 minutes, as was previously described by Bersezio et al. ${ }^{14}$ The occlusal dentin area was measured via the computer software ImageJ, widely used in medicine ( $\mathrm{NIH}$, USA), with a photographic record of the disk and a known and standardized distance, with a Nikon D3100 (Nikon, Japan).

Hydraulic Conductance $(\mathrm{CH})$ was calculated using the following formula:

$$
C H=F / A \cdot \Delta P \bullet t
$$

Were $\mathrm{CH}$ corresponds to hydraulic conductance expressed in $\mu \mathrm{L} \cdot$ $\mathrm{cm}-2 \cdot \mathrm{H} 2 \mathrm{O} \cdot \mathrm{min}-1 \mathrm{~cm}-1, \mathrm{~F}$ corresponds to flow rate expressed in $\mu \mathrm{L} /$ $\min ; \mathrm{A}$ is the area of occlusal dentin exposed in $\mathrm{cm} 2 ; \Delta \mathrm{P}$ corresponds to the difference of hydrostatic pressure through the dentin (which corresponds to the height of the column of distilled water in these case $20 \mathrm{~cm}$ ); and the variable $\mathrm{t}$ is time in minutes.

\section{Statistical Analysis}

Data were subjected to the statistical tests Shapiro-Wilk, ONE-WAY ANOVA and post hoc Tukey to compare between all groups, performed using the computer software SPSS 21.0 for Windows (SPSS, IBM, New York, USA).

\section{Sample size}

$\mathrm{N}$ was obtained based on previous studies in the literature. ${ }^{14,15} \mathrm{It}$ was calculated with a statistical power of 0.8 , considering a statistical difference between groups with an alpha of 0.05

\section{RESULTS}

Figure 1 visually demonstrates and compares the mean hydraulic conductance of the experimental groups with different passive evaporation times. Table 1 displays the control group when compared to the experimental groups, based on results obtained from the ANOVA and post hoc Tukey tests $(\rho<0.05)$. Briefly, a statistically significant difference in hydraulic conductance values was detected upon comparing the GC (control group) with each of the other experimenta groups $(\rho<0.05)$, yet with no statistically significant difference between the experimental groups $(\rho<0.05)$.

\section{DISCUSSION}

The results obtained from this ex vivo study relate to the influence/ effect of passive solvent evaporation on the hydraulic conductance of human dentin. Findings suggest differences between the control group (minimum evaporation time considering the application // a cavity that take 10 seconds maximum) and experimental groups. Therefore, the authors concluded to reject the null hypothesis.

In this study, a Single Bond Universal (SBU) adhesive was employed, in which its composition contains water and ethanol as solvents; other solvents commonly used in adhesive systems include acetone, the latter being the most volatile, and if not properly used, it can desiccate the dentin. The ability of the adhesive to infiltrate the collagen phase of the dentin it is attributed to the solvent. Furthermore, an effective solvent action is directly related to its proper evaporation, since high

\section{Hydraulic conductance by groups}

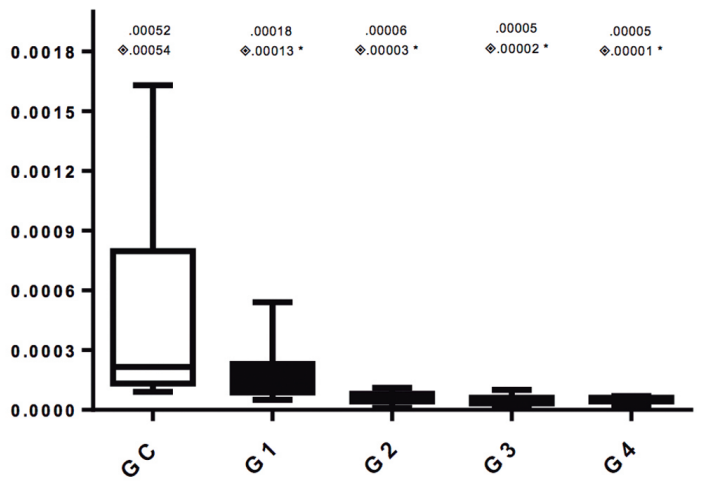

Figure 1. Hydraulic conductance of different groups (Average and standard deviation). ${ }^{*}=(p<0.05)$ compared to control group. $Y$ axis (hydraulic conductance expressed in $\mu \mathrm{L} \cdot \mathrm{cm}-2 \cdot \mathrm{H} 2 \mathrm{O} \cdot \min -1 \mathrm{~cm}-1$ ) and $\mathrm{X}$ axis (groups)

Table 1. Comparison between groups ( $x$ and y axis) by post-hoc Tukey test ( $p$ values)

\begin{tabular}{lccccc}
\hline & Control & G1 & G2 & G3 & G4 \\
\cline { 2 - 6 } Control & 1,000 & 0,000 & 0,000 & 0,000 & 0,000 \\
G1 & & 1,000 & 1,000 & 1,000 & 1,000 \\
G2 & & & 1,000 & 1,000 & 1,000 \\
G3 & & & & 1,000 & 1,000 \\
G4 & & & & & 1,000
\end{tabular}

levels of solvent in the adhesive layers can inhibit the polymerization, thereby affectively modifying the mechanical properties of the adhesive layers. ${ }^{11}$

Previous studies have reported that the degree of conversion for different adhesive systems is associated with the solvent evaporation method used. ${ }^{16}$ For example, in 2012, Borges et al. found that the degree of monomer conversion in adhesives using solvents such as water and alcohol, is influenced by the solvent evaporation method and the type of monomer present. On the other hand, the use of acetone as a solvent was not influenced by these factors. ${ }^{17}$ Pashley et al. reported in 1998 that it is more difficult to evaporate the water when mixed with HEMA as the functional monomer, and that the residual water will interfer with polymerization of the monomers. ${ }^{7}$ Here in, we used the Single Bond Universal adhesive which presents HEMA and MDP, with water/alcohol as the solvents; thereby the obtained results consistent with solvent evaporation time would improve the dentinal seal, given a lower hydraulic conductance value/function.

Several studies have evaluated the influence of different times of passive solvent evaporation on pellets of different materials and records of teeth, where the degree of conversion, bond strength and differences depending on the type of solvent evaporation and formulation of adhesive, were measured. ${ }^{11,16-19}$ However, to the best of knowledge, no scientific insightful studies showing how the hydraulic conductance is affected, exist. Here in, our findings demonstrate that there is a diminution of the hydraulic conductance, as the evaporation time increases. This is relevant since the clinician applying hybridization is also searching for a better dentinal seal and dentin-pulp complex protection. Therefore, passive solvent evaporation should be a clinical step that is not overlooked. In this study, a time of 50 minutes was used as a positive control as at such time, all solvent would have evaporated ${ }^{18}$. It is noteworthy that this study was conducted using a single layer of adhesive; as was reported earlier by Aranda et al. where the number of layers of adhesive applied will impact the resulting and measured hydraulic conductance. ${ }^{20}$

Based on our findings herein, the importance of solvent 
passive evaporation would not be only limited for achieving proper polymerization of the adhesive, yet, to ensure a proper sealing of the dentinal tubules, as well. As mentioned above, this is indeed an important aspect affecting post-operative sensitivity, since it has been reported that poor infiltration of the adhesive and thus an inadequate occlusion of dentinal tubules lead to fluid movement within the dentina tubules thereby generating sensitivity sensations; as proposed via the renowned Branstom hydrodynamic theory.

Finally, despite the known and expected limitations of an ex vivo study, a passive evaporation of at least 30 seconds post-applying the adhesive, to polymerize, is recommended. This is deemed sufficient especially considering that when the delay was set for a longer delay, similar observations and outcomes still resulted. Our planned future studies will combine the solvent evaporation methods (active and passive) and further evaluate the mechanical and rheological properties alongside the degree of conversion of the adhesive systems; undeniably, exhilarating to reveal.

\section{CONCLUSION}

We conclude that with a passive evaporation of more than 30 seconds, an improved dentinal seal is achieved, thereby significantly reducing the hydraulic conductance values. While more studies are desirable, this protocol is suggested for clinical use.

\section{Reference}

1. Mjor IA. Dentin permeability: the basis for understanding pulp reactions and adhesive technology. Braz Dent J.2009; 20(1): 3-16.

2. Ajcharanukul O, Oranratmanee K, Thitikunakorn S. Effect of different osmotic stimuli on fluid flow before and after self-etching adhesive application. J Adhes Dent.2010; 12(2): 103-8.

3. Pashley DH ,Carvalho RM. Dentine permeability and dentine adhesion. J Dent.1997; 25(5): 355-72.

4. Reis AF, Oliveira MT, Giannini M, De Goes MF ,Rueggeberg FA. The effect of organic solvents on one-bottle adhesives' bond strength to enamel and dentin. Oper Dent 2003; 28(6): 700-6.

5. Krithikadatta J. Clinical effectiveness of contemporary dentin bonding agents. J Conserv Dent.2010; 13(4): 173-83.

6. Manuja N, Nagpal R ,Pandit IK. Dental adhesion: mechanism, techniques and durability. J Clin Pediatr Dent.2012; 36(3): 223-34.

7. Pashley EL, Zhang Y, Lockwood PE, Rueggeberg FA ,Pashley DH. Effects of HEMA on water evaporation from water-HEMA mixtures. Dent Mater.1998; 14(1): 6-10.

8. Paul SJ, Leach M, Rueggeberg FA, Pashley DH. Effect of water content on the physical properties of model dentine primer and bonding resins. J Dent.1999; 27(3): 209-14.

9. Jacobsen T, Soderholm KJ. Some effects of water on dentin bonding. Dent Mater.1995; 11(2): 132-6.

10 Nunes TG, Garcia FC, Osorio R, Carvalho R, Toledano M. Polymerization efficacy of simplified adhesive systems studied by NMR and MRI techniques. Dent Mater.2006; 22(10): 963-72.

11. Argolo S, Oliveira DC, Fontes CM, Lima AF, de Freitas AP,Cavalcanti AN. Effect of increased dwell times for solvent evaporation on the bond strength and degree of conversion of an ethanol-based adhesive system. Acta Odontol Latinoam.2012 25(1): 109-14
12. Miyazaki M, Platt JA, Onose $\mathrm{H}$, Moore BK. Influence of dentin primer application methods on dentin bond strength. Oper Dent.1996; 21(4): 167-72.

13. Loguercio AD, Loeblein F, Cherobin T, Ogliari F, Piva E , Reis A. Effect of solvent removal on adhesive properties of simplified etch-and-rinse systems and on bond strengths to dry and wet dentin. J Adhes Dent 2009: 11(3): 213-9.

14. Bersezio C, Martin J, Xaus G, Vildosola P, Oliveira OB, Jr., Moncada G, et al. Influence of type of bur and acid etching on dentin hydraulic conductance. Acta Odontol Latinoam.2013; 26(3): 131-7.

15. Hevia J, Fresno, C, Martín, J, Moncada, G, Letelier, C, Oliveira Junior, OB, \& Fernández, E. Modelo de conductancia hidráulica de la dentina humana ex vivo. Rev Clin Periodoncia Implantol Rehabil Oral.2013; 6(3): 114-7.

16. Giannini M, Arrais CA, Vermelho PM, Reis RS, dos Santos LP, Leite ER. Effects of the solvent evaporation technique on the degree of conversion of one-bottle adhesive systems. Oper Dent.2008; 33(2): 149-54.

17. Borges BC Souza-Junior EJ, Brandt WC Loguercio AD, Montes MA, Puppin-Rontani RM, et al. Degree of conversion of simplified contemporary adhesive systems as influenced by extended air-activated or passive solvent volatilization modes. Oper Dent.2012; 37(3): 246-52.

18. Ikeda T, De Munck J, Shirai K, Hikita K, Inoue S, Sano H, et al. Effect of evaporation of primer components on ultimate tensile strengths of primer-adhesive mixture. Dent Mater.2005; 21(11): 1051-8.

19. Ito S, Hoshino T, lijima M, Tsukamoto N, Pashley DH ,Saito T. Water sorption/ solubility of self-etching dentin bonding agents. Dent Mater.2010; 26(7): 617-26.

20. Aranda L BC, Martin J, Vildósola P, Xaus G, Moncada G, Oliveira Junior OB, Fernández $\mathrm{E}$. Influencia del número de capas de adhesivo en la conductancia hidraúlica en dentina humana. Revista Dental de Chile.2013; 104(3): 3-6. 